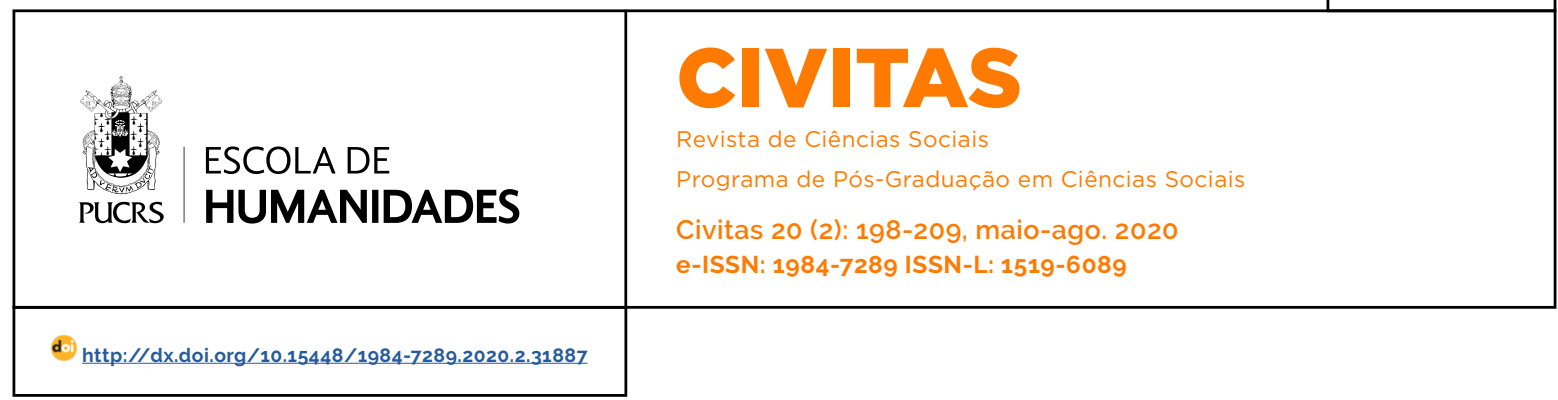

DOSSIÊ: MEIO-AMBIENTE EM DISPUTA

\title{
Desenvolvimento sustentável empresarial: práticas e concepções sobre sustentabilidade na cadeia produtiva do plástico verde
}

\author{
Business sustainable development: practices and conceptions on sustainability in the \\ green plastic productive chain \\ Desarrollo sostenible empresarial: prácticas y concepciones sobre sostenibilidad en la \\ cadena productiva de plástico verde
}

\section{Rodrigo Foresta Wolffenbüttel ${ }^{1}$ orcid.org/0000-0002-3417-563X rodrigoforesta@gmail.com}

\section{Sandro Ruduit Garcia²} orcid.org/0000-0002-7060-2678 sandro.ruduit@ufrgs.br

Recebido em: 13 set. 2018 Aprovado em: 6 mai. 2019 Publicado em: 4 ago. 2020

\section{(c) (i)}

Artigo está licenciado sob forma de uma licença Creative Commons Atribuição 4.0 Internacional.
Resumo: A partir do pressuposto que economias de mercado são reguladas por ordens sociais que regulam ou limitam as trocas com base em convenções, normas e valores, o presente estudo busca investigar o conjunto de sentidos atribuídos à sustentabilidade pelos atores empresariais e sua transformação em cursos de ação produtiva e econômica nas empresas. Uma vez que a sustentabilidade se refere a um valor em constante disputa e a efetividade dos sentidos atribuidos a ela depende da representação sobre a sua validade, a pesquisa voltou-se para as concepções de sustentabilidade e de transformações promovidas por empresas que aderiram ao plástico verde, um plástico cuja matéria-prima é renovável. A análise dos dados aponta para uma concepção de sustentabilidade como um modelo de gestão endógeno ao negócio, sensivel às críticas e às contestações, mas perpassado por suas limitações em relação ao crescimento econômico. Os resultados apontam, ainda, para a relevância da sustentabilidade na construção de expectativas que permitem a complexa coordenação de ações diversas no processo econômico capitalista.

Palavras-chave: Sustentabilidade empresarial. Mercados. Sociologia econômica. Plástico verde.

Abstract: Based on the assumption that market economies are regulated by social orders that regulate or limit trades based on conventions, standards and values, the present study seeks to investigate the set of meanings attributed to sustainability by business actors and their transformation in courses of action in companies. Since sustainability refers to a value in constant dispute and the effectiveness of the meanings attributed to it depends on the representation about its validity, the research turned to the conceptions of sustainability and transformations promoted by companies that adhered to the green plastic, a plastic whose raw material is renewable. The analysis of the data points to a conception of sustainability as an endogenous management model for the business, sensitive to criticisms and challenges, but permeated by its limitations in relation to economic growth. The results also point to the relevance of sustainability in the construction of expectations that allow the complex coordination of diverse actions in the capitalist economic process. Keywords: Corporate sustentability. Markets. Economic sociology. Green plastic

Resumen: A partir del supuesto de que las economías de mercado están reguladas por órdenes sociales que regulan o limitan los intercambios con base en convenciones, normas y valores, el presente estudio busca investigar el conjunto de sentidos atribuidos a la sostenibilidad por los actores empresariales y su transformación en cursos de acción productiva y económica en las empresas. Una vez que la sustentabilidad se refiere a un valor en constante disputa y la efectividad de los sentidos atribuidos a ella depende de la representación sobre su validez, la investigación se volvió a las concepciones de sustentabilidad y transformaciones promovidas por empresas que se adhieren al plástico verde, un plástico cuya 
materia prima es renovable. El análisis de los datos apunta a una concepción de sostenibilidad como un modelo de gestión endógeno al negocio, sensible a las críticas y contestaciones, pero atravesado por sus limitaciones en relación al crecimiento económico. Los resultados apuntan a la relevancia de la sostenibilidad en la construcción de expectativas que permiten la compleja coordinación de acciones diversas en el proceso económico capitalista.

Palabras clave: Sostenibilidad empresarial. Mercados Sociología económica. Plástico verde

\section{Introdução}

Há certo consenso entre analistas sociais de que a noção de sustentabilidade tem orientado, mundialmente, o curso de ação de atores sociais diversos - movimentos sociais, empresas, consumidores e governos - em relação à questão ambiental (Abramovay 2012; Almeida e Premebida 2014; Garcia 2017; Hommel e Godard 2005; Veiga 2010). Sabe-se que empresários, em particular, têm ocupado posição privilegiada no processo de construção da noção, constituindo-se, como lembra Sartore (2012), em protagonistas na discussão sobre desenvolvimento sustentável na Rio +20. A esse despeito, é comum tratar as práticas de responsabilidade social e ambiental das empresas como se fossem nocivas distorções nos mecanismos de mercado, ou como transformações meramente discursivas, movidas por interesses econômicos e políticos.

Essas duas formas de abordar a questão refletem concepções naturalizadas e imutáveis sobre a economia capitalista, como uma esfera autônoma autorregulada, em que as empresas são imunes à contestação social e reagem nos termos estritos da regulação e dos incentivos formais do aparato estatal. Com isso, tornam-se relativamente escassas as análises que se debruçam sobre os modos de inserção dos diferentes tipos de empresas na questão ambiental e seus reflexos em práticas produtivas concretas. O presente estudo busca fornecer uma perspectiva alternativa a essas abordagens ao indagar sobre o conjunto de sentidos atribuídos à sustentabilidade pelos atores empresariais e sua transformação em um curso de ação produtiva e econômica nas empresas.

O pressuposto básico da pesquisa é de que mesmo economias de mercado são reguladas por ordens sociais que incidem na mercabilidade dos objetos de troca, nas suas condições e na participação dos possiveis interessados, com base em tradições, convenções e normas sociais (Weber 2009). Nestes termos, a coordenação de um curso de ação empresarial dependeria não apenas dos interesses, das regras e dos aparatos administrativos formalmente instituidos, mas também de representações empíricas sobre valores sociais no interior de uma ordem afirmada como legitima (Weber 2009). O sentido da ação econômica sustentável é, desse prisma, construido desde uma concorrência - ou disputa - entre diferentes grupos pela apropriação dos critérios que dão validade à noção (Schluchter 2014). A contestação de valores que fundamentam ordens econômicas abriria questões sobre as expectativas que permitem coordenar as diferentes ações econômicas, como crédito, investimento, inovação e consumo (Beckert 2017).

Com base na investigação de empresas que investiram em uma inovação considerada sustentável, o argumento proposto na análise é de que as controvérsias ambientais estão presentes em organizações empresariais. As empresas constroem sentidos sobre sustentabilidade que envolvem expectativas relacionadas às interdependências da cadeia em que se situam, geração e adoção de novas tecnologias, mudança nos padrões de consumo, e transparência e responsabilidades perante impactos do negócio. Tais concepções operam como imagens que lhes permitem coordenar transformações de suas ações produtivas e econômicas, como o desenvolvimento ou difusão de inovações, a adoção de práticas de gestão dos recursos mais atentas aos seus efeitos no tempo-espaço e a busca de legitimação social. Neste sentido, a sustentabilidade que adjetiva o desenvolvimento afirma-se como um valor social, em meio às atuais controvérsias ambientais, refletindo-se no sentido das ações empresariais.

O artigo volta-se para as concepções empresariais sobre sustentabilidade e seus reflexos na transformação de sistemas produtivos e nas relações com diferentes partes interessadas, observando-se a experiência de empresas que investiram no chamado plástico verde. Esse 
surgiu em meio a um processo de contestação social (Hommel e Godard 2005) do plástico convencional protagonizado por ONGs e por grupos ambientalistas junto a órgãos públicos. O plástico verde foi desenvolvido por uma empresa química brasileira, detendo as mesmas propriedades materiais e fins de utilização do plástico convencional. Difere, porém, quanto à matéria prima renovável de sua composição (o etanol), em lugar do uso de matéria prima fóssil (o petróleo), caracterizando, assim, uma origem renovável que the rende um "selo verde". Por essa razão, o plástico verde contribui para a agenda dos "Objetivos do Milênio" que visa à redução das emissões dos gases de efeito estufa. As empresas que investem nessa inovação encontram-se, em geral, pressionadas por valores e padrões de qualidade do mercado internacional, relativamente mais competitivos. Ademais, pesa nessa decisão a crescente procura e preocupação de consumidores por produtos com menor potencial agressivo ao ambiente, além de políticas públicas municipais de discriminação e de proibição da distribuição de produtos considerados agressivos, como sacolas plásticas (Wolffenbüttel 2015).

A pesquisa desenvolveu-se junto a sete empresas que aderiram ao plástico verde no contexto nacional, mediante entrevistas semiestruturadas realizadas com gestores ao longo dos anos de 2014 e 2015. Esses dados foram categorizados, tendo em vista a apreensão dos sentidos atribuidos à noção de sustentabilidade e das práticas consideradas sustentáveis pelos representantes das empresas. As práticas foram divididas em duas dimensões de análise: transformações produtivas e organizacionais; e relações com as partes interessadas. Essas dimensões auxiliaram na apreensão da concepção de sustentabilidade compartilhada pelas empresas e de sua representação, vigência dos critérios de validade que conformam a ordem social. Para tanto, foi elaborada uma proposta de análise de conteúdos temática não aprioristica dessas categorias, mediante um esforço de apreensão dos seus sentidos manifestos e latentes - categorias êmicas (Bardin 2011). As seções seguintes deste artigo dividem-se em quatro partes. Na primeira parte, são brevemente revisadas as origens e os contornos teóricos da concepção de sustentabilidade associada ao desenvolvimento, bem como as principais disputas em torno do tema. Na segunda, são apresentados e analisados os sentidos atribuidos à sustentabilidade pelas empresas em seus discursos. A seção seguinte é destinada à análise das práticas produtivas e organizacionais das empresas investigadas, orientadas para o valor sustentabilidade. Finalmente, as conclusões apontam para os limites e as potencialidades da concepção de sustentabilidade empresarial, conforme observada neste estudo, ressaltando o caráter processual e contingente do processo de legitimação de valores sociais em ordens econômicas.

\section{Concepções em disputa}

A questão sobre as relações entre ambiente e sociedade adquire destaque e contornos mais nítidos, a partir dos anos 1960, quando as causas ambientais passam a disseminar-se na opinião pública e começam a tomar forma de movimentos de massa. Essa expansão ganha força neste século, guardando relações com ambiguidades geradas pelo desenvolvimento cientifico e tecnológico, como novos patamares de intervenção humana na natureza - notadamente a biotecnologia - combinados com a produção e a disseminação de conhecimentos que se tornam fundamento para a ação em favor das causas ambientais. Ademais, a agenda ambiental nutre-se do alongamento de nossas percepções sobre tempo-espaço, como na defesa das solidariedades intergeracionais e na compreensão de que o problema tem status internacional. A despeito dessa expansão recente, as ideias sobre preservação da natureza remontam às elites intelectualizadas do século 19, remanescentes da aristocracia que fora abalada pela industrialização na Europa. No início do século 19, a qualidade ambiental esteve, também, presente nos ideais comunais e utópicos do anarquismo nos Estados Unidos e na Europa (McCormick 1992; Varandas 2013).

Pode-se, hoje, falar de uma questão ambiental, na medida em que as relações das sociedades 
industriais com o ambiente passaram a ser institucionalmente interrogadas pelas pressões exercidas por grupos ecologistas, pelos discursos político-partidários e pela construção de uma opinião pública cada vez mais sensibilizada pela qualidade ambiental. Com isto, abrem-se disputas entre entendimentos coletivos fundados sobre diferentes valores sociais (Almeida e Premebida 2014). Mesmo que os adversários sejam mais ou menos comuns (desenvolvimento industrial descontrolado e órgão governamentais ineficientes), os movimentos ambientais assumem caracteristicas e agendas diversas, desde grupos de "amantes da natureza" e de comunidades de contracultura até comunidades em defesa da qualidade de vida local em face de agentes poluidores (McCormick 1992). No entanto, o maior destaque e influência na agenda pública têm sido alcançados por movimentos internacionalistas, com desdobramentos nas mídias e no sistema político-partidário, preocupados com a proteção ambiental, conformando mundialmente a noção de desenvolvimento sustentável.

Os criticos alertam que essa agenda leva ao simples gerenciamento científico-tecnológico dos impactos do capitalismo no ambiente, reivindicando pautas que vão além do problema da resiliência dos ecossistemas, como questões sobre as interfaces entre sociedade e natureza, sobre valores "intrínsecos" da sociedade, e sobre o encanto e refúgio da natureza (Alphandéry et al. 1991). Tais questões são aguçadas no contexto da expansão exponencial do modo de vida industrial-racional-capitalista. Estudiosos como Alphandéry et al. (1991) e Almeida (1997) constatam que as potencialidades revolucionárias dos movimentos ambientais, que se apresentavam como um novo paradigma cultural, têm pendido mais para uma lógica reformista do modelo de mercado do que para uma revolução no modelo de sociedade. Os movimentos voltam-se, hoje, predominantemente, para a proteção do ambiente por intermédio da avaliação da poluição e dos desequilibrios resultantes do excesso produtivo e populacional.

O fato é que a agenda ambientalista ganhou força no último quarto do século passado, quando o controverso substantivo desenvolvimento passou a contar com o adjetivo sustentável para expressar um novo projeto político e modelo de desenvolvimento, preocupado com as consequências da ação humana sobre o ambiente, com a finitude dos recursos naturais e com a continuidade da própria existência humana. Um conceito voltado para as necessidades da presente geração sem comprometer a capacidade de as gerações futuras satisfazerem suas necessidades (Brundtland 1987). Para Rist (2008), o conceito de desenvolvimento sustentável é paradoxal e envolve a inserção da realidade em uma perspectiva diferente, transformando o problema do desenvolvimento, e suas consequências intervencionistas, em solução desejável. Segundo Nobre e Amazonas (2002), o conceito é deliberadamente vago em função do processo de institucionalização da problemática ambiental na política internacional, cuja ambiguidade visa a mediar posições até então inconciliáveis na arena internacional - de um lado, o combate à pobreza; de outro, os crescentes problemas ambientais.

Ao deixar em aberto a forma de lidar com o desafio das solidariedades intergeracionais, a noção instaura uma arena de disputas em torno das suas dimensões envolvidas e dos seus sentidos (Nascimento 2012). Em razão da complexidade e indeterminação dessa controvérsia pública e cientifica, a sustentabilidade tem sido disputada em termos da definição de critérios e parâmetros que the dão conteúdo e sentido específicos. Esse é o caso do plástico verde, por exemplo, que se propõe a capturar $\mathrm{CO} 2$ por meio de sua matéria prima renovável, a cana-de-açúcar. Critério que se encontra em concordância com as principais diretrizes da Organização das Nações Unidas (ONU) e do Painel Intergovernamental sobre Mudanças Climáticas (IPCC), no combate às mudanças climáticas, mas suscita contestações sobre a prática da monocultura ou sobre a cultura de consumo baseada no uso do plástico.

Ao passar do âmbito dos acordos internacionais para as políticas públicas e instituições de mercados em âmbito nacional, essa disputa suscita, igualmente, debates entre movimentos sociais, associações civis, empresas, partidos e instituições governamentais sobre os sentidos da 
sustentabilidade, conforme uma pluralidade de interesses e capacidades diversas desses atores. Nestes termos, as associações e as federações empresariais têm demonstrado especial interesse nessa temática, como indicam a criação do Conselho Empresarial Brasileiro de Desenvolvimento Sustentável (CEBDS), em 1997, os fundos de investimento sustentáveis, os índices de sustentabilidade empresarial, os relatórios de sustentabilidade, os selos verdes e as certificações voltadas para a gestão ambiental, como ISO 14001, ${ }^{3}$ ISO 26000 (Sartore 2012).

As pressões e as contestações sociais em face dos crescentes problemas ambientais têm influido na forma como os atores percebem o funcionamento da ordem econômica e, por conseguinte, orientam reciprocamente suas ações. Isso se aplica às rotinas das organizações empresariais (Fligstein 2001), expressando-se nos modelos de gestão do trabalho, nas definições das relações entre empresas e na adoção de inovações em processos e produtos. Note-se a criação de departamentos voltados exclusivamente para tratar de questões vinculadas ao ambiente, a partir do surgimento de instrumentos administrativos, tais como as Licenças Ambientais, que estabelecem condições e restrições para instalação, ampliação e operação das empresas.

Portanto, a emergência da sustentabilidade como um valor legítimo nesta ordem econômica estaria vinculada às dinâmicas de competitividade empresarial, contestação social, justificação e regulação administrativo-institucional (Weber 2009). Daí o interesse em investigar mais de perto como a emergência desse valor e sua representação pelas empresas transformou suas ações em relação à ordem econômica, aos seus participantes e ao ambiente.

\section{Os sentidos atribuídos à sustentabilidade}

Neste estudo, o conceito de representação refere-se à validade de uma ordem, sendo, nesses termos, uma representação empírica sobre a vigência de um valor que se torna a causa de uma ação (Schluchter 2014; Weber 2009). Isto é, a representação sobre a validade de uma ordem é compreendida não como uma moral externa e coesa, que se desenvolve autonomamente e impõe-se aos indivíduos, mas como o entendimento subjetivo que os atores, mutuamente referidos, têm sobre a vigência dos conteúdos de sentido que conformam a ordem em questão.

Para que uma ordem seja legítima, mais que sua vigência jurídica, é necessário que ela seja considerada empiricamente válida pelos atores. Logo, a coordenação da ação baseia-se na probabilidade da ação, em referência a outros, ser orientada com base em "ordens que o agente conhece como leis e convenções 'em vigor', isto é, das quais ele sabe que sua transgressão provocará reações de terceiros" (Weber 2009, 20).

O processo de reconhecimento da sustentabilidade como valor legítimo no mercado do plástico envolve uma série de modificações na maneira de se conceber a relação da sociedade com o ambiente. O tom reformista dessas modificações traduz-se na manutenção de uma concepção instrumental daquela relação, mas adquire consciência das consequências envolvidas no uso abusivo dos recursos naturais. Como antes mencionado, as empresas acabam formulando sentidos sobre sustentabilidade que são próprios aos seus interesses, em razão não apenas da ambiguidade presente nas propostas de desenvolvimento sustentável, mas também da complexidade envolvida nos desdobramentos futuros das práticas atuais. Logo, a sustentabilidade refere-se a um valor ao qual os atores atribuem certo sentido que orienta transformações na ação empresarial. Os conteúdos desse valor são interpretados pelos atores empresariais em meio à coordenação da relação entre suas ações (concorrentes, consumidores, fornecedores, financiadores) e as ações de atores sociais considerados relevantes (acionistas, governantes, clientes, funcionários, movimentos sociais).

\footnotetext{
3 A série ISO 14001 consiste na certificação de um grupo de padrões e diretrizes relacionadas com a gestão ambiental. Já a ISO 26000 versa sobre a responsabilidade social, expressa pelo desejo e pelo propósito das organizações em incorporarem considerações socioambientais em seus processos decisórios e a responsabilizar-se pelos impactos de suas decisões e atividades na sociedade e no meio ambiente. Esta é uma norma de uso voluntário. Inmetro. 2013. Dados estatísticos. Acessado em 14 out. 2018, http://www.inmetro.gov.br/ gesta014001/dados_estat.asp?Chamador=INMETRO14\&tipo $=$.
} 
Essa reorientação da ação empresarial está vinculada à reconfiguração dos mercados, às pressões e às expectativas sociais, assim como possiveis sanções morais e financeiras. Nesse sentido, envolve a ressignificação e a proposição desses conteúdos à luz dos interesses dos atores empresariais. Por isso, a pesquisa voltou-se para os sentidos atribuidos à noção de sustentabilidade no interior dessa ordem econômica e às ações produtivas e organizacionais decorrentes dessa orientação.

As empresas investigadas, por meio de entrevistas semiestruturadas com seus representantes, são: uma empresa multinacional de origem brasileira do ramo químico e petroquímico, detentora da patente e produtora do plástico verde (a); duas indústrias nacionais intermediárias da cadeia petroquímica, produtoras de embalagens e sacarias plásticas (b, c); e quatro empresas consumidoras que utilizam o plástico verde em suas embalagens, uma gigante nacional do ramo de cosméticos (d), uma empresa da região sudeste de alimentação animal (e), e duas multinacionais de produtos de higiene e limpeza pessoal e produtos para a saúde (f, g).

Essas empresas foram escolhidas por serem precursoras na adesão ao plástico verde e por suas variadas posições na cadeia produtiva. Segundo informações da empresa detentora da patente do produto, este já foi utilizado por mais de 50 marcas de forma não necessariamente continua, significando a adesão de um número expressivo de empresas ao plástico verde e a sua proposta sustentável. Neste sentido, pode ser considerado um grupo heterogêneo de empresas, espalhadas geograficamente, cujo principal elo é a adesão a esse produto voltado para a sustentabilidade. A cadeia produtiva envolve usinas de etanol, que fornecem a matéria-prima para o plástico; indústrias petroquímicas, que transformam o etanol em resinas termoplásticas; indústrias intermediárias de transformadores plásticos, que transformam as resinas em sacarias, filmes, embalagens, componentes plásticos com diferentes finalidades; e empresas consumidoras que utilizam estas embalagens para seus produtos, ou como componentes.

As entrevistas foram realizadas de forma a apreender o conteúdo do valor sustentabilidade, isto é, o conjunto de sentidos atribuidos à noção, bem como a série de ações e de transformações produtivas e organizacionais orientadas para esse valor. Procedeu-se análise de conteúdo temática não apriorística, buscando em um primeiro momento utilizar as categorias êmicas mobilizadas pelos representantes empresariais a partir das questões formuladas em torno do entendimento sobre sustentabilidade e as ações tomadas pelas empresas nessa direção. No momento seguinte, essas categorias foram aglutinadas em unidades de significado mais amplas e abstratas, e ordenadas conforme a frequência com que elas ocorrem entre as empresas investigadas. Contudo, o foco da investigação repousa menos na recorrência dos conteúdos e mais em suas correlações e sistematização.

Na análise dos sentidos atribuidos à sustentabilidade, foram mobilizadas pelas empresas as seguintes categorias para sua definição: gestão do impacto do negócio; a partir critérios objetivos de legitimação; de forma sistêmica e interdependente; baseada em um padrão tecnológico mais eficiente; voltada para o futuro; e vinculada a um novo padrão de consumo (quadro 1).

Quadro 1 - Concepção de sustentabilidade a partir dos sentidos atribuídos pelas empresas

\section{Sentidos atribuídos à noção de sustentabilidade}

I. Gestão do impacto do negócio com base nos três pilares (econômico, social, ambiental) II. Critérios de legitimação com base em instrumentos técnicos e auditorias externas

III. Sistêmica e baseada na interdependência da cadeia

IV. Padrão tecnológico mais eficiente

V. Voltada para o futuro (vinculada a sobrevivência do negócio)

VI. Novo padrão de consumo

Fonte: Elaborado pelos autores. 
Essas categorias expressam o conteúdo de sentido do valor sustentabilidade para essas empresas, isto é, um valor que regularia a ação empresarial, de forma que essa perceba a necessidade de gerir seus impactos (I) como uma estratégia para garantir sua própria sobrevivência no mercado (V), como um novo modelo de negócio, mais eficiente (IV), transparente (II) e interdependente (III). Essa concepção se encontra em concordância com as máximas do desenvolvimento sustentável, de manejo racional dos recursos finitos e de redução dos impactos ao ambiente, em vista ao futuro de nossas gerações.

Tal concepção considera compativel o crescimento econômico e o aumento da qualidade ambiental, baseando-se no equilibrio entre os pilares social, ambiental e econômico. Quando instigados sobre a expansão do consumo, o aumento de recursos necessários e seus danos ao ambiente, foi mobilizada como fundamental pelos entrevistados a necessidade de crescer para atender as demandas populacionais, mediante o crescimento equilibrado com base em tecnologias mais limpas e eficientes. Os entrevistados percebem o consumo e o crescimento econômico como algo inerente a essa lógica. Em alguns casos, existe a consciência de que a expansão das atividades, ainda que nos parâmetros sustentáveis, contribui para o aumento geral do impacto ambiental da empresa. Contudo, ao atribuir o equilibrio aos três pilares como meta, as empresas justificam seu impacto ambiental com base nos impactos sociais e econômicos que causariam caso não crescessem economicamente. Essa percepção suscita importantes considerações em relação ao crescimento econômico e suas implicações para extratos sociais diretamente vinculados a estas atividades, que não devem ser ignoradas, em especial em economias em desenvolvimento.

Contudo, segundo as entrevistas, a garantia desse equilibrio depende do estabelecimento de metas transparentes que se vinculam a práticas aprovadas pela alta liderança das empresas. Trata-se de estabelecer critérios objetivos (II), passiveis de serem verificados por auditores e órgãos externos, que possibilitem a avaliação do cumprimento das condutas, diferenciando essas empresas daquelas que praticam um falso marketing, desvinculado de práticas efetivas e de meios de sua comprovação. Nesse aspecto, a racionalidade formal desempenha um papel importante na legitimação das práticas sustentáveis. A quantificação e a formalização dos impactos ambientais de forma sistêmica e interdependente permitem a avaliação da conduta das empresas e a própria gestão de suas metas em comparação com os aspectos econômicos.

Neste sentido, a concepção de sustentabilidade empresarial está ligada a uma continuidade da lógica expansionista do capitalismo moderno, com base em uma "nova ética", vinculada às consequências ambientais da atividade industrial (I), mas disposta a uma reestruturação a partir de inovações sustentáveis. Trata-se de uma concepção de sustentabilidade integrada ao modelo de negócio, voltada para o uso eficiente dos recursos e orientada à redução dos impactos envolvidos em suas atividades, uma sustentabilidade endógena ao negócio, constituindo-se, pois, uma via para a inovação e o desenvolvimento da empresa (IV). Um exemplo desta aposta na melhoria dos processos e no desenvolvimento de inovações sustentáveis como vetores de transformação para uma base produtiva mais eficiente e limpa encontra-se no próprio desenvolvimento do plástico verde, inovação voltada para mercados preocupados com os índices de emissão de $\mathrm{CO} 2$.

Dentre as empresas investigadas, foram observados diferentes graus de complexidade e sofisticação dos argumentos mobilizados. Enquanto algumas relacionaram todos os sentidos, inclusive tratando os três pilares do desenvolvimento (ambiente, economia e sociedade) como algo intrínseco e não necessariamente contraditório, outras trabalhavam com ideias de compensação relativas aos efeitos colaterais de sua atividade econômica. A própria noção de sustentabilidade variava em relação a sua abrangência e sua interdependência com a sociedade (V), em sentidos mais estritos era entendida como a sustentabilidade do negócio, ao passo que nos argumentos mais elaborados aparece como algo interdependente de mudanças mais amplas na sociedade. 
Esta variação na complexidade da concepção de sustentabilidade, além de traduzir diferentes percepções sobre a natureza das empresas e a forma como elas se relacionam com a sociedade, vincula-se às ações empresariais orientadas para a sustentabilidade, como será visto a seguir.

\section{Práticas produtivas e organizacionais sustentáveis}

Essa concepção de sustentabilidade das empresas visitadas orienta suas ações, promovendo alterações nas formas de organização da produção e nas relações com as partes interessadas. Segundo Beckert (2017), a coordenação das ações econômicas, que são sempre reciprocas, depende, no capitalismo, de imagens e expectativas de futuro dos agentes. As representações e expectativas levam a certa convergência de propósitos diante da incerteza, da indeterminação e, em especial, das crises, constituindo-se orientações cognitivas na integração das fases do processo econômico: crédito, investimento, inovação e consumo.
A partir da divisão em duas dimensões de análise (transformações produtivas e organizacionais; relações com as partes interessadas), a pesquisa identificou uma série de práticas que expressam os principais sentidos de sustentabilidade. Em relação às transformações produtivas e organizacionais destacam-se: a gestão alongada do tempo e do espaço na organização da produção, gestão racional dos recursos naturais finitos, o manejo dos impactos da produção sobre o ambiente, o desenvolvimento de inovações sustentáveis, a difusão interna de práticas mais eficientes, e a busca de legitimação com bases externas (quadro 2). Dessas categorias, as três primeiras podem ser consideradas o núcleo das transformações produtivas que se orientam pela noção de sustentabilidade. As empresas investigadas afirmaram realizar, no momento das entrevistas, ações voltadas para a utilização mais eficiente dos recursos naturais, para minimização dos impactos envolvidos em suas atividades, com base em períodos maiores e fronteiras mais amplas de sua cadeia produtiva.

Quadro 2 - Práticas consideradas sustentáveis

\begin{tabular}{|c|c|}
\hline Transformações produtivas e organizacionais & Relações com as partes interessadas \\
\hline I. Gestão alongada do tempo / espaço & VII. Monitoração reflexiva voltada para a crítica \\
II. Finitude dos recursos & \\
III. Manejo dos impactos & VIII. Mecanismos de justificação \\
IV. Inovações sustentáveis & \\
V. Legitimação externa & IX. Ampliação da cadeia \\
VI. Difusão de práticas &
\end{tabular}

Fonte: Elaborado pelos autores.

Essa orientação se expressa em processos produtivos que geram menos perdas, que são capazes de reaproveitar recursos, ou que utilizam matérias-primas renováveis. São condutas compativeis com a concepção sobre a finitude dos recursos naturais e sobre a necessidade de geri-los com base em uma racionalidade formal. A adesão a produtos e processos mais eficientes permite o uso mais racional e responsável dos recursos naturais (I), contribuindo assim para a sustentabilidade da atividade produtiva. As empresas visitadas mobilizam a categoria da finitude dos recursos (II) e a durabilidade do plástico para justificar seu uso, em resposta às críticas ao consumo de plástico e às tentativas de substituí-lo por outros materiais, relativizando seus impactos. Por conseguinte, as categorias de gestão de recursos finitos e de manejo de impactos podem ser contraditórias: um processo pode ser mais eficiente, consumindo menos recursos e gerando menos perdas, mas pode envolver um produto que seja mais agressivo ao ambiente. A noção de sustentabilidade, contudo, envolve uma complementaridade entre essas categorias. Por seu turno, a redução do impacto da atividade empresarial sobre o ambiente (III) 
ocorre, principalmente, por meio de alterações no processo que visam a reduzir ou a tratar a emissão de poluentes (atmosféricas, resíduos sólidos, efluentes líquidos), por meio da instalação de filtros, reprocessamento de correntes, tratamentos de efluentes, uso de insumos menos agressivos e redução de emissões.

Muitas das empresas investigadas (a, d, f, g) fazem uso de técnicas e instrumentos capazes de mensurar as emissões em todo seu processo. Chamada de gestão de carbono na cadeia de valor, esse conjunto de práticas conta com estudos de Análise do Ciclo de Vida (ACV) e planilhas que visam a mensurar o inventário das emissões realizadas pelas empresas, de forma a poder minimizá-las. Além disso, todas afirmaram mensurar os impactos ambientais em relação aos volumes produzidos ( $\mathrm{tCO}_{2} / \mathrm{t}$ de produto, $\mathrm{m}^{3} \mathrm{de}$ água/t de produto), e apresentam, na maioria dos casos (emissão de gases de efeito estufa, consumo de energia, consumo de água, geração de residuos), reduções significativas. Todavia, como o crescimento econômico não é problematizado, esta redução na intensidade do impacto por volume produzido não significa necessariamente uma redução absoluta do impacto ambiental, pois uma empresa pode desenvolver processos e produtos mais eficientes, mas seguir expandindo sua produção e seu impacto absoluto.

É importante notar que essas três categorias nucleares da sustentabilidade na dimensão produtiva - gestão alongada (I), uso racional de recursos (II) e manejo de impactos (III) - encontram-se intimamente vinculadas às inovações sustentáveis (IV). Essa lógica de aplicação de inovações tecnológicas aos processos produtivos com base em formas mais limpas de produção aproxima-se da tese de que a contínua modernização da produção possibilita a manutenção do crescimento econômico sobre bases menos agressivas ao ambiente. $O$ descolamento entre crescimento econômico e fluxos materiais e energéticos parece ser um dos fundamentos da sustentabilidade, na perspectiva empresarial. Ademais, o fato de todas as empresas mobilizarem as mesmas categorias nessa dimensão aponta para uma coordenação conjunta dessa ação, baseando-se na probabilidade de outros atores considerarem essa orientação válida, configurando assim novas concepções de controle para esse mercado (Beckert 2017; Fligstein 2001; Weber 2009).

Ainda nessa dimensão, outras duas categorias formuladas a partir das entrevistas aparecem em menor intensidade, a difusão de práticas sustentáveis $(\mathrm{VI})$, por meio de treinamentos e de capacitações aos funcionários e lideranças, e a legitimação externa (V), por intermédio da adequação a parâmetros e sujeição a auditorias de órgão certificadores externos. Ambas se vinculam à ideia do valor sustentabilidade como algo dependente de instrumentos técnicos e de garantias externas para sua legitimação e relacionam-se à dimensão de análise seguinte.

No que se refere à dimensão das relações com as partes interessadas, as categorias elaboradas apresentaram certa recorrência. Porém, nesse particular foi ressaltado novamente o grau de articulação entre as práticas e a concepção de sustentabilidade. As mesmas empresas que apresentaram uma concepção mais interdependente de sustentabilidade elaboraram formas de gestão mais abertas e atentas às demandas sociais, aderiram a critérios e a metodologias externas para atestar a sustentabilidade das práticas e dos produtos, e adotaram uma percepção ampliada de sua responsabilidade em todos os momentos da cadeia produtiva. A vigência dos critérios que orientam as condutas, nessa dimensão, é categorizada em: monitoração reflexiva da crítica (VII), desenvolvimento de mecanismos de justificação (VIII), e ampliação das relações da cadeia (IX).

A monitoração reflexiva da ação empresarial refere-se a práticas de consulta e de pesquisa voltadas para as demandas e as pressões dos grupos sociais considerados relevantes para as empresas. Essas se acham interessadas na sua reputação e imagem pública. Uma expressão dessa conduta é a formulação de matrizes de materialidade que 
são elaboradas em conjunto com stakeholders. Com isso, elaboram suas estratégias de ação sobre os impactos considerados mais relevantes. Porém, outras formas de consulta, como ouvidorias, seguem a mesma lógica recursiva de modificar suas ações com base em demandas sociais. Segundo essa lógica, as empresas não devem se limitar aos aspectos coercitivos das normas, mas proporem novas formas, desenvolverem novas tecnologias e estabelecerem limites mais rígidos para suas emissões com base nos interesses das partes interessadas. Contrariando a lógica neoclássica de que os preços conteriam toda a informação necessária, essas empresas estariam atentas às possiveis fontes de contestação social de suas atividades e às novas oportunidades de mercado (Abramovay 2012).

Como lembram Boltanski e Chiapello (2009), as empresas buscam integrar parcialmente as críticas formuladas a fim de justificar e legitimar suas atividades, refletindo-se nas transformações produtivas e organizacionais antes analisadas. Isso envolve programas e campanhas voltados para a conscientização ambiental, promoção de eventos culturais, prêmios e peças publicitárias, além de soluções que integram uma parcela da comunidade, como centros de formação e capacitação profissional. Essa postura reflexiva das empresas está vinculada à legitimação da sustentabilidade, aos riscos de contestação social e às oportunidades de mercado envolvidas, ou seja, é um dos elementos desse processo recursivo de modificação das condutas empresariais. No contexto estudado, percebe-se que a partir dessas demandas e pressões, as empresas comprometidas com os parâmetros de sustentabilidade não só alterariam suas práticas de forma a legitimar suas atividades, mas também divulgariam essas ações de forma a ganhar mais visibilidade para seus públicos. Esses mecanismos de justificação (VIII) atuariam com base nas críticas, buscando neutralizá-las ou incorporá-las parcialmente ao processo.

A terceira categoria dessa dimensão, menos recorrente entre as empresas, relaciona-se com as mudanças na produção com base na gestão alongada do espaço, mais especificamente com a representação ampliada do ciclo produtivo (IX). Em conformidade com essa categoria, as empresas adotaram uma percepção ampliada de sua cadeia produtiva, tornando-se corresponsável pelos impactos que ocorrem em outras etapas do processo. Esse tipo de relação com fornecedores e consumidores favorece a difusão de práticas e estratégias organizacionais voltadas para a sustentabilidade. Essa orientação da ação promove a seleção de fornecedores com base na adesão de práticas sustentáveis e o monitoramento de condutas ou participação em consultas com clientes, formas de expandir a sustentabilidade do seu ciclo produtivo.

Por exemplo, a empresa petroquímica (a) desenvolveu um código de conduta para seus fornecedores de etanol, que devem obedecer alguns princípios em relação à redução de queimadas, à preservação da biodiversidade, às boas práticas ambientais, ao respeito aos direitos humanos e às práticas trabalhistas, e ao fornecimento de informações para a realização dos estudos de ACV. Além disso, realiza auditorias externas para verificar o cumprimento desses princípios. Já a empresa de cosméticos (d), estimula seus fornecedores a desenvolverem práticas pautadas pela sustentabilidade, porém sempre realiza estudos de ACV antes de aderi-las ou contabilizá-las no seu inventário de carbono.

Portanto, de acordo com tais práticas, os limites relativos às responsabilidades das empresas estendem-se para além das fronteiras comerciais ou produtivas. A relação com as partes interessadas - por intermédio de canais de consulta, pesquisas de reputação e matrizes de materialidade - configura-se como um sistema aberto, em que essas partes atuam fornecendo informações, contestando e pressionando por alterações. Em contrapartida, as empresas responderiam, incorporando parte das demandas, críticas e detratores ao seu escopo e divulgando, posteriormente, em uma lógica recursiva, seus resultados em busca de justificação e legitimação de suas atividades. Essas práticas, em conformidade com esse tipo de orientação, demonstram não apenas a imbricação social das empresas, mas também a sua tenta- 
tiva de aumentar a sintonia dessa comunicação de maneira a tirar o máximo proveito da relação.

\section{Considerações finais}

O estudo sobre a representação de validade do valor sustentabilidade entre empresas que investiram no plástico verde e sua transformação em ações compreende o sentido disputado e atribuido pelos agentes no interior de uma ordem considerada legitima (Schluchter 2014; Weber 2009). Os resultados obtidos mostram, ainda, a relevância da noção de sustentabilidade na construção de expectativas que permitem a complexa coordenação de ações diversas no processo econômico capitalista (Beckert 2017; Weber 2009).

Cabe sublinhar que as empresas visitadas tendem a interpretar, em conformidade com seus interesses, tanto o conjunto de regras formalmente instituídas quanto as expectativas sociais em relação aos problemas ambientais, cuja não observação implica desaprovação social. Isso se reflete em interpretações formalistas e instrumentais da sustentabilidade no interior da ordem econômica vigente. De qualquer modo, o processo reflete-se recursivamente nas condutas das empresas investigadas, que interpretam o valor sustentabilidade não de forma passiva e automática, mas, pelo contrário, procuram atuar reflexivamente sobre a própria noção, construindo e legitimando-a a partir de um conjunto de critérios e convenções - tais como, critérios de eficiência energética, tratamento de efluentes, emissão de gases do efeito estufa, pós-consumo - com vistas a adequarem-se às novas formas socialmente aceitas de produzir, tentando compatibilizá-las com os pressupostos do crescimento econômico.

As mudanças antes registradas apontam para alterações significativas em convenções e normas consideradas legitimas na ordem econômica. Se é verdade que essas transformações podem ser tomadas como insuficientes perante desequilibrios ambientais, também é fato que elas representam, no contexto atual, um elevado grau de interdependência entre a ação empresarial e a emergência de novos valores sociais. A ordem econômica encontra-se sempre inserida no interior de outras ordens sociais. Ou seja, essas organizações são "moldadas por fatores que, longe de exprimir uma essência imutável, refletem circunstâncias históricas que podem ser transformadas pela intervenção humana" (Abramovay 2012, 194). São expressivas as novas propostas de relacionamento com clientes, fornecedores e comunidades por parte das empresas que utilizam o plástico verde, tendendo a ampliar os limites relativos às responsabilidades das empresas para além das fronteiras comerciais ou produtivas e difundir práticas a partir de sua lógica interdependente. Isso é diferente dos enclaves industriais do passado.

Nos casos mais elaborados, configura-se um sistema aberto: as partes atuam fornecendo informações, contestando e pressionando por alterações, por intermédio de canais de consulta, pesquisas de reputação e matrizes de materialidade. Trata-se de empresas que adotaram a sustentabilidade como um modelo de gestão endógeno ao negócio, sensivel à crescente legitimação dos valores sustentáveis, mas perpassado por suas limitações em relação ao crescimento econômico. Os modos e tipos de crescimento econômico, como um dos propulsores da organização empresarial, também podem ser considerados um valor, sendo, portanto, passiveis de transformação pela dinâmica do julgamento público.

\section{Referências}

Abramovay, Ricardo. 2012. Muito além da economia verde. São Paulo: Ed. Abril.

Almeida, Jalcione. 1997. A problemática do desenvolvimento sustentável. In Desenvolvimento sustentável: necessidade e/ ou possibilidade? organizado por Dinizar F. Becker. Santa Cruz do Sul: Edunisc.

Almeida, Jalcione e Adriano Premebida. 2014. Histórico, relevância e explorações ontológicas da questão ambiental. Sociologias 16 (35): 14-33. https://doi. org/10.1590/S1517-45222014000100002.

Alphandéry, Pierre; Pierre Bitoun e Yves Dupont. 1991. O equivoco ecológico: riscos políticos. São Paulo: Brasiliense.

Barbosa Júnior, Afonso F.; Rafael M. de Morais; Sebastião F. Emerenciano; Handson C. D. Pimenta; Reidson P. Gouvinhas. 2008. Conceitos e aplicações da Análise do Ciclo de Vida (ACV) no Brasil. Revista Gerenciais 7 (1): 39-44. 
Bardin, Laurence. 2011. Análise de conteúdo. São Paulo, Edições 70.

Beckert, Jens. 2017. Reimaginando a dinâmica capitalista: expectativas ficcionais e o caráter aberto dos futuros econômicos. Tempo Social 29 (1): 165-189. https://doi. org/10.11606/0103-2070.ts.2017.119003.

Boltanski, Luc e Chiapello, Ėve. 2009. O espírito do capitalismo e o papel da crítica. In O novo espirito do capitalismo, organizado por Luc Boltanski e Ėve Chiapello, 31-80. São Paulo: Martins Fontes.

Brundtland, Gro Harlem (org.). 1987. Nosso futuro comum. Editora da FGV.

Daly, Herman. 2004. Crescimento sustentável, não obrigado. Ambiente \& Sociedade 7 (2). https://doi. org/10.1590/S1414-753X2004000200012.

Fligstein, Neil. 2001. Mercado como política: uma abordagem político-cultural das instituições de mercado. Contemporaneidade e Educação 9 (1): 26-55.

Garcia, Sandro R. 2017. Sentido das mudanças: economia criativa e suas implicações sociais em Porto Alegre. Ciências Sociais Unisinos 53 (1): 15-23. https:// doi.org/10.4013/csu.2017.53.1.02.

Hommel, Thierry e Olivier Godard. 2005. Contestação social e estratégias de desenvolvimento industrial: aplicação do modelo da gestão contestável a produção industrial de OGM. In Organismos geneticamente modificados, organizado por Marcelo Dias Varella e Ana Flavia Barros-Platiau, 251-284. Belo Horizonte: Del Rey.

McCormick, John. 1992. Rumo ao paraiso: a história dos movimentos ambientalistas. Rio de Janeiro: Relume-Dumará.

Nascimento, Elimar Pinheiro do. 2012. Trajetória da sustentabilidade: do ambiental ao social, do social ao econômico. Estudos Avançados 26 (74): 51-64. https:// doi.org/10.1590/S0103-40142012000100005.

Rist, G. 2008. The history of development: from western origins to global faith. 3 ed. London: Zed Books.

Sartore, Marina de Souza. 2012. Da filantropia ao investimento socialmente responsável: novas distinções. Caderno CRH 25 (66): 451-464. https://doi.org/10.1590/ S0103-49792012000300005.

Schluchter, Wolfgang. 2014. O desencantamento do mundo: seis estudos sobre Max Weber. Rio de Janeiro: Editora UFRJ.

Varandas, Maria José. 2013. As raizes europeias do ambientalismo norte-americano: Rousseau no novo mundo. Perspectiva Filosófica 1 (39): 123-138.

Veiga, José Eli da. 2010. Sustentabilidade: a legitimação de um novo valor. São Paulo: Senac.

Weber, Max. 2009. Economia e sociedade. v. 1. 4 ed. São Paulo: Editora UnB.

Wolffenbüttel, Rodrigo Foresta. 2015. Sustentabilidade e ação socioeconômica: a rede produtiva do plástico verde. Dissertação de Mestrado em Sociologia, Ufrgs, Porto Alegre.

\section{Rodrigo Foresta Wolffenbüttel}

Doutor em Sociologia pela Universidade Federal do Rio Grande do Sul (Ufrgs), Porto Alegre, RS, Brasil. Professor substituto no Instituto Federal do Rio Grande do Sul (IFRS), Porto Alegre, RS, Brasil.

\section{Sandro Ruduit Garcia}

Doutor em Sociologia pela Universidade Federal do Rio Grande do Sul (Ufrgs), Porto Alegre, RS, Brasil. Professor adjunto do departamento de Sociologia e do Programa de Pós-Graduação em Sociologia da Universidade Federal do Rio Grande do Sul (Ufrgs), Porto Alegre, RS, Brasil. 